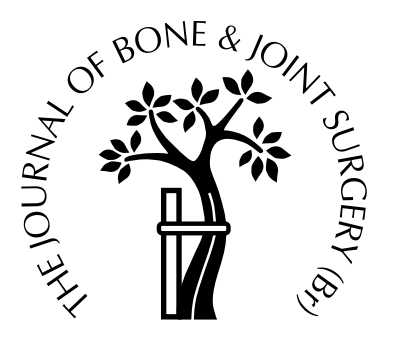

\title{
Editorial
}

\section{THE NATIONAL JOINT REGISTRY FOR ENGLAND AND WALES}

In July 1972 Sir John Charnley, in internal publication 39 from Wrightington Hospital, wrote "Serious consideration should be given to establishing a Central Register to keep a finger on the pulse of total implant surgery on a nation-wide basis. Surgeons should not be permitted to perform total hip implant work unless prepared to have weekly returns made of the operations as they are performed, and hereafter to have patients questioned annually by circular from the Registry". The Minister of Health has now agreed that a national Registry should be set up. It is to be conducted entirely electronically, and the contract for the management of this has been agreed with AEA Technology for an initial period of three years. A Steering Group of 17 members has been appointed. The Chairman was a direct choice of the Government and the remainder have been nominated by the Department of Health. There are only two orthopaedic surgeons. The Vice-Chairman is Professor Paul Gregg, and Hugh Phillips is the appointee of the British Orthopaedic Association.

Although the co-operation of individual orthopaedic surgeons is not mandatory, the hospital trusts will be expected to obtain full compliance. Government funding is to be made available for the first 18 months, after which the Registry will be financed by a levy on individual prostheses. This will be collected by AEA Technology from the manufacturing companies. The collection of information will depend on suitable access to the appropriate IT network for all surgeons who undertake joint replacement.

The organisation of this Registry is to be quite different to that of other countries or indeed of the smaller registries which are currently operating in the UK. These are all controlled by orthopaedic surgeons. They are able to utilise the information and make it available to all the participants. The current registries, particularly those in Sweden, Norway and the Trent region in England, have made useful contributions to the understanding and monitoring of total joint replacement. Their findings have been made available to all who are interested and have contributed to the understanding of these procedures to a considerable degree.

(C)2003 British Editorial Society of Bone and Joint Surgery

doi:10.1302/0301-620X.85B1.14063 \$2.00

J Bone Joint Surg [Br] 2003;85-B:1-2.
The Registry for England and Wales will be different in that it is to be controlled by the Department of Health. Although the Steering Group is in place, it has not yet been able to advise as to how the material is to be used. It seems that it is likely to produce an annual report which will present demographic data. There will be no details of the preoperative assessment of the patients. The Registry will simply record details of the initial procedure without follow-up or outcome unless a revision is undertaken. It is not known as yet whether individual surgeons will have access to their own results. To what extent will these be used to monitor individual prostheses, individual hospitals or, indeed, individual surgeons? Is the aim of the Registry purely scientific or does it have a political connotation? It is not clear how the data are to be analysed or with whom lies the responsibility for the dissemination of the observations which have been made. What are the arrangements for the academic use of the material?

The Registry is to be welcomed, and is long overdue. Its structure, however, is a cause for concern. Fear has been expressed that the information gathered will be used for government management of joint replacement. Will attempts be made to control the use of particular prostheses, as has been attempted, to a degree, by the National Institute of Clinical Excellence (NICE)? If individual surgeons are not thought to be up to the mark, will their practice be questioned, and, if so, by whom?

The advantages of joint registries have been widely canvassed. They provide an audit of practice. In the earlier days of the Swedish and Norwegian Hip Registries, it was possible to demonstrate particular types of prosthesis which performed badly. These were eventually withdrawn from use. However, improvements in design and in the technique of implantation have been such that differences in performance are now much less obvious. The recent problems in the UK concerning the use of the $3 \mathrm{M}$ prosthesis indicate that a proper audit may well suggest the possibility of early failure. However, such an audit would have to be carefully tailored to detect early potential problems. It would be necessary to carry out annual reviews in the early stages in order to find evidence of faults and the logistical problems which this would produce would be considerable. Unless there is virtually full compliance by surgeons in this exercise the audit will be of limited value. There seems to have 
been no attempt to consider the implications in cost of such a regular appraisal. Assessment of the information which has been gathered can only be carried out by experienced orthopaedic surgeons and this will require time, organisation and money. How are these to be made available?

The objective of the Registry has not been defined. Is it simply to be a list of procedures performed with assessment of the rate of failure if a revision is required? Surely, the Registry should produce much more detailed information. If it is to be undertaken on the lines which appear to be cur- rently envisaged, it will simply replicate information which is already available from the Scandinavian registries. Is this what is really required?

Orthopaedic surgeons have campaigned for a national registry for many years. It is pleasing to see that this will now come about, but it must be set up to provide the maximum amount of data which it is practicable to gather so that the art and science of joint replacement can continue even more successfully than at present.

Frank Horan

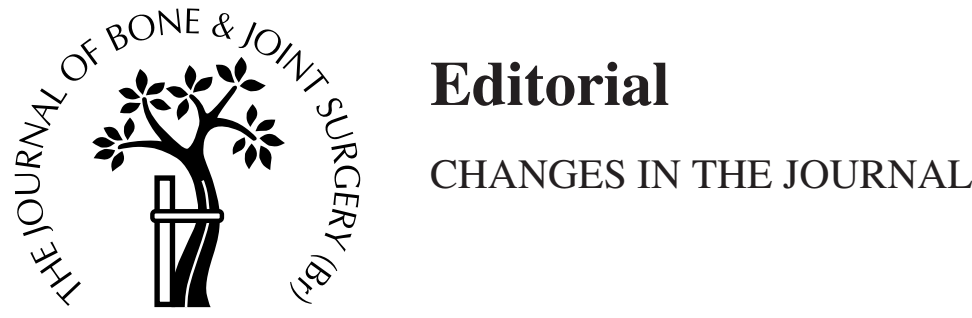

The survey of our readership which was carried out last year indicated that many readers would appreciate further review or instructional articles which summarised the current knowledge of particular topics. The review article which appears in each issue helps to fulfil this need, but we feel that there is a place for shorter appraisals of topics of contemporary interest. We are therefore introducing regular short reviews under the general title of 'Aspects of Current Management'. The first of these appears in this issue and deals with the complications of arthroscopic reconstruction of the anterior cruciate ligament. These articles are aimed at the general orthopaedic surgeon and the trainee. We hope that their form and content will appeal to our readers.

There have also been changes in the Guide to Authors. It is most important that authors adhere to the instructions which it contains in order that they may present their papers in a manner which will appeal to the reviewers.

Because of the increasing use of electronic publication it has been necessary to amend the assignment of copyright to the Journal. When papers are accepted authors will be sent the appropriate form for signature. It will not be possible to publish papers unless the authors agree to this condition.

Frank Horan 